\title{
Strategic Research on Staff Sports in Hebei Province and the Powerful Province in Sports as Well as Development of National Fitness -North China Pharmaceutical Group is Taken as an Example for The Large State-Owned Pharmaceutical Corporation
}

\author{
Yan $\mathrm{Li}^{1,2}$ \\ ${ }^{1}$ Hebei Institute of Physical Educational \\ 050041 \\ Email: 878578182@qq.com
}

\author{
Rong $\mathrm{He}^{1}$ \\ 2. Institute of Physical Education, Hebei Normal \\ University050024 \\ 82 Xuefu Road, Shijiazhuang, Hebei 050041 \\ China
}

\begin{abstract}
Through the documentation method, interview method and questionnaire survey, the staff-sport current situation of North China Pharmaceutical Group is investigated; the management system, current situation and the existing shortcomings can be found; according to the current situation and the existing problems of the staff sports, many suggestions are proposed in this paper, including enhancing the publicity efforts, changing the working thought, increasing the investment in the staff sports and improving the sports participation, so as to better promote the development and improvement of the staff sports.
\end{abstract}

Keywords-Hebei Province, staff sports, North China Pharmaceutical Group, current situation, countermeasures

North China Pharmaceutical Group Co., Ltd is one of the largest pharmaceutical enterprises in China; for more than 50 years since establishment, the company has been ranked into the top 500 enterprises with the largest scale and the best economic benefit for years based on its scale advantage, technological advantage and quality advantage; awarded the title of "the national excellent enterprise of quality management", and rated as the "national customer satisfaction enterprise" for years. Employees are the production subject of the pharmaceutical group; the steady and healthy development of the enterprise is directly dependent on the sound construction of the staff forces. During the construction of the staff forces in the pharmaceutical industry, the staff sport is an indispensable and organic component; this shows the irreplaceable value in terms of improving the comprehensive quality of the corporate employees, enhancing the corporate cohesive force and promoting the corporate cultural construction.

I. THE CURRENT SITUATION OF THE STAFF-SPORT DEVElOPMENT IN HEBEI NORTH CHINA PHARMACEUTICAL GROUP

\section{A. Staff-sport management in Hebei North China \\ Pharmaceutical Group}

The staff-sport management mode of the large state-owned pharmaceutical enterprise in Hebei province -North China Pharmaceutical Group is reflected in establishing the sport propaganda department involved with the staff-sport management department; the professional sport manager is responsible for the staff-sport activity; and equipped with the grass-roots staff sport association; the leader of the labor union is hired as the chairman of the staff sport association, and responsible for enhancing the leadership of the staff sport activity. The contents and modes of the sport activities vary with the social development and the staff requirements. The leader of staff sports activities only plays the guiding and supervisory role in the development and planning of the sports activities and the important activities, so as to guarantee the healthy development of the staff-sport activities.

\section{B. Construction of the staff-sport teams in Hebei North China Pharmaceutical Group}

The organizational construction of sports in North China Pharmaceutical Group achieves some effects, makes positive contribution to the staff-sport development, and plays an positive role in organizing and guiding the employees to do physical fitness and exercise. Since 1988, the labor union organization of North China Pharmaceutical Group has established a total of four staff sport associations, one club and two sports teams. The activities would held for 7 15 times each year, and the number of participants is 7000 8000.The ball games are frequent, and the employees always take active part. Therefore, it reflects that the staff-sport organization and management system is increasingly mature and perfect, but still difficult to meet due to the increasing demands for the spiritual culture and new sports.

\section{The physical exercise of Hebei North China Pharmaceutical Group}

1) The purpose of participating in physical exercise. According to the survey, 237 people think that physical training participation is aimed to keep fit, accounting for 64.2\%; and 163 people believe that physical training participation aims at the entertainment and recreation, and pressure relief and reduction, accounting for $44.2 \%$; it also can be seen from the above survey results: the main purpose that the employees in North China Pharmaceutical Group participate in physical exercise include two aspects: one is to keep fit, the other is to feel 
happy, release and reduce pressure.

2) The time for participating in physical exercise and the frequency of participating in physical exercise per week. According to the survey shown in Table 1, 143 employees can guarantee to do physical exercise for more than three times a week, accounting for $38.8 \%$ of the total respondents; while $32.7 \%$ of the respondents only occasionally participate in or do not participate in the physical exercise; it may be related to the working hours of a great majority of employees; they will do less physical exercise on working days but do more on holidays.

Table 1 Frequency that employees participate in physical exercise

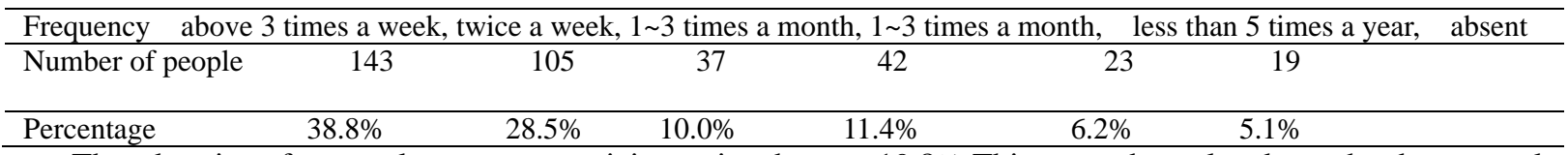

The duration for employees to participate in the physical exercise will mainly last less than 30 minutes, accounting for about 51.2\%; and followed by 30 60 minutes, accounting for $29.0 \%$; the time range for more than 1 hour is at a minimum with a percentage of
$19.8 \%$.This may be related to the busy work of the employees and the concept that the manual labor can replace the physical exercise or related to the way and habits of participating in the physical exercise.

Table 2: The time for employees to participate in the physical exercise each time

\begin{tabular}{lccc}
\hline Time for each exercise & less than 30 minutes & $30 \sim 60$ minutes & more than 1 hour \\
\hline Number of people & 189 & 107 & 73 \\
\hline Percentage & $51.2 \%$ & $29.0 \%$ & $19.8 \%$ \\
\hline
\end{tabular}

3) Site selection for employees to participate in physical exercise. In terms of the site selection for participating in physical exercise, the first three choices for employees in North China Pharmaceutical Group are public places including park, the free sport places, roads or streets. All these places are free. Some employees select the non-free sports place; although it is not a big proportion, there is still a certain growth trend; spending money on health is gradually accepted by the people.

4)The physical exercise items that the employees participate in. According to the survey statistics shown in Figure 1, the top five exercise items that the employees from North China Pharmaceutical Group participate in are: running, martial arts, aerobics, walking and dancing. These items are not subject to the site and equipment, easy to be done everywhere, and favored by lots of employees accordingly. It also can be found from the survey that the male workers prefer the exercise items with strong confrontation, fierce competition and large exercise load, such as the basketball, table tennis and volleyball. The female workers prefer the gentle and

\section{The situation of staff-sport consumption in Hebei North China Pharmaceutical Group}

1)The level of staff-sport consumption.The sport consumption level refers to the quantity of various sports material products and labor service products consumed for the purpose of satisfying the life needs in a certain period, and reflects the level of individual sports consumption in a certain period. The annual average sports consumption of employees in North China Pharmaceutical Group is mainly concentrated between 101 and 400 Yuan, and 101 200 Yuan is dominant. The annual average sports consumption is in medium level, and the sports consumption consciousness is gradually entertaining exercise items with medium or small-sized load, such as the aerobics and dancing.

Selection of exercising items that employees participate in

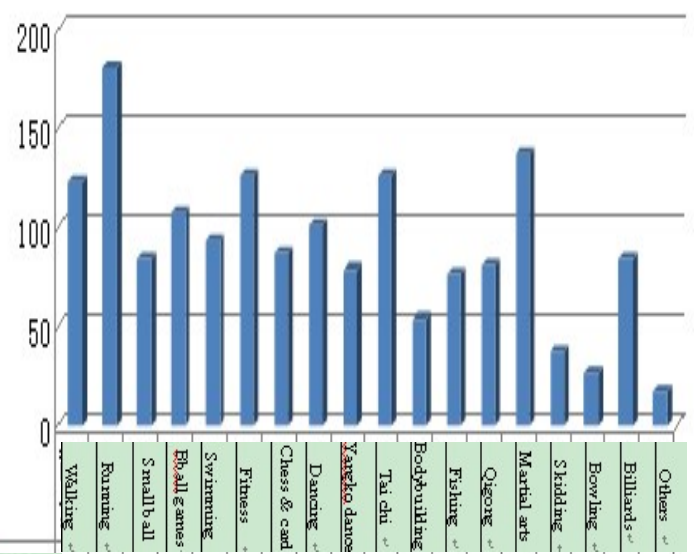

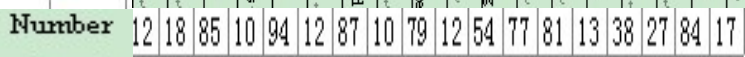
of people

FIGURE 1 SELECTION OF EXERCISING ITEMS THAT EMPLOYEES PARTICIPATE IN

formed

2) The staff-sport consumption structure. Sports consumption structure refers to the proportion of various sports in the total consumption and the correlation. The material consumption of employees in North China Pharmaceutical Group mainly includes the purchase of tangible products, such as the sportswear, fitness equipments, sports newspapers and magazines. In the staff-sport consumption, the material sports expenditure accounts for a vast majority, and becomes the "general direction" of the current staff-sport consumption. Through in-depth investigation and statistical analysis, it is found that the consumption ability of the recreational 
sports in the employees from North China Pharmaceutical Group is on the low side. The expenditures of recreational sport consumption are divided into two parts: one is the tickets for sports events; the other is the costs for participating in the activities in the stadium.

\section{ANALYSIS ON THE FACTORS WHICH AFFECT THE STAFF-SPORT DEVELOPMENT OF THE LARGE STATE-OWNED ENTERPRISES IN HEBEI PROVINCE -NORTH CHINA PHARMACEUTICAL GROUP}

Through interviewing with the sports affairs managers and the specific organizers, as well as the panel discussion with the front-line employees, most employees think the shortage of sports space and busy work are the main reason to affect their participation in sports activities. However, in the opinions of the corporate executives, the managers and organizers of the sport activities, the staff-sport development is closely related to the emphasis of the executives, the propaganda intensity, the systems of rewards and penalties, the sports funds, sports venues and the equipment situation, but has little to do with the employees' prejudice against the physical fitness, objection to the sports or there is no time to participate in the sports activities due to the busy work.

\section{THE STAFF-SPORT DEVELOPMENT COUNTERMEASURES OF THE LARGE STATE-OWNED ENTERPRISES IN HEBEI PROVINCE -NORTH CHINA PHARMACEUTICAL GROUP}

Through the survey and analysis on the staff-sport current situation in North China Pharmaceutical Group, the basic characteristics and main problems of the sports for employees in North China Pharmaceutical Group are analyzed. Some countermeasures are proposed according to these problems, it is hoped to provide some help for the staff-sport development of North China Pharmaceutical Group, even the staff-sport development of the large state-owned enterprises in the whole Hebei province.

\section{A.Increase the publicity of the sports knowledge, instruct \\ the employees to have a comprehensive understanding of sports}

The sport propaganda department of the sport competent department in labor union should pay attention to the propaganda activities of the staff-sport knowledge, and disseminate the basic knowledge of sports in the way of sports knowledge contest, brochure and blackboard newspaper, expand the influence of staff sports; advocate the scientific, healthy and civilized lifestyle and instruct the employees to take active part in the physical exercise.

\section{B. Change the old working thought, renovate the ideas}

Introduce the specialized managerial talents for sports, strengthen the construction and management of facilities in sports venues, open up the stadiums to the employees for a fee but continuously improve the preferential policy for employees, cultivate the sports backbone, maintain and carry forward the original fine tradition of the enterprise, attach great importance to the reform and innovation of the contents and methods for the corporate sports activities, and further enrich the staff-sport activities.

\section{Improve the participation degree of staff-sport exercise activities}

Connect the frequency of the employees' participation in sports activities with the salary, assessment, in pursuit of advanced workers and bonus; establish the staff-sport evaluation index system, consider the allocation of the facilities that the workers require according to different ages, gender and nature of work, so as to make the employees do well in the allocation between work and exercise, and increase the possibility and enthusiasm of the employees to participate in the sports activities.

\section{Increase the capital investment in the staff sports; introduce the specialized talents for staff sports}

Increase the investment in staff sports, introduce the specialized physical instructors who are responsible for instructing the staff sports, so as to connect it closely with the corporate cultural construction, and make the staff-sport activities can be held in an organized, planned and step-by-step way. Strengthen the construction of staff-sport facilities, and stress on supporting the construction of the sports association and club within the enterprise, and gradually meet the fitness demands for a majority of employees.

\section{REFERENCES}

[1] Yang Wenxuan ,Yang Ting. Introduction to Sports. Higher Education Press.2006.157-158

[2] Qin Chunlin, Wang Kaizhen, Xiao Linpeng. Organization and management of sports fitness activities. Beijing Sport University Press. 224-237

[3] Gap Yinhua. Analysis on the current situation of sport activities of oil-field employees in Henan province [master's dissertation]. 2010.5.

[4] Wang Junhong, Investigation and research on the current situation of sports for employees in Henan large state-owned coal mining enterprises master's dissertation]. 2010.5.

Li Yan (1979 - ), Associate professor, doctoral candidates, Research Interests: Sociology of Sport 。

The survey subject of investigating the people's livelihood with the social development in Hebei province Serial number: 201301214 